\title{
Oficina de Origami: Um recurso estratégico para o ensino de Geometria
}

\author{
Origami Workshop: A strategic resource for teaching Geometry \\ Taller Origami: Un recurso estratégico para la enseñanza de la Geometría
}

Recebido: 21/06/2021 | Revisado: 29/06/2021 | Aceito: 04/07/2021 | Publicado: 15/07/2021

Arnaldo Dias Ferreira
ORCID: https://orcid.org/0000-0002-1487-8477
Instituto Federal de Educação Ciência e Tecnologia do Ceará, Brasil
E-mail: adias.matematica@gmail.com
Elaine de Farias Giffoni de Carvalho
ORCID: https://orcid.org/0000-0002-8574-5620
Universidade Federal do Ceará, Brasil
E-mail: elainegdecarvalho@gmail.com
Lara Ronise de Negreiros Pinto Scipião
ORCID: https://orcid.org/0000-0003-0263-4026
Universidade Federal do Ceará, Brasil
E-mail: larascipiao@gmail.com
Francisco Régis Vieira Alves
ORCID: https://orcid.org/0000-0003-3710-1561
E-mail: fregis@ifce.edu.br
Instituto Federal de Educação Ciência e Tecnologia do Ceaŕ, Brasil
Maria José Costa dos Santos
ORCID: https://orcid.org/0000-0001-9623-5549
Universidade Federal do Ceará, Brasil
E-mail: mazeautomatic@gmail.com

\section{Resumo}

Este artigo é um estudo descritivo-exploratório, do tipo relato de experiência e objetiva apresentar os resultados obtidos na oficina: "Origami, Geometria e Diversão", realizada no VIII Diálogos da Matemática com a Pedagogia (DIMA). O procedimento metodológico dessa oficina foi pautado de acordo com os pressupostos da metodologia Sequência Fedathi (SF), com base em suas fases: Tomada de posição, Maturação, Solução e Prova; e se deu por meio da investigação em sala de aula, utilizando como técnicas de coleta de dados, a observação dos sujeitos e aplicação de um questionário avaliativo. Como principais resultados, observou-se que na Tomada de Posição, com a situação-problema proposta, os participantes, principalmente os estudantes do Curso de Pedagogia da Faculdade de Educação da Universidade Federal do Ceará, tiveram dificuldades em identificar os conceitos geométricos nos Origamis e que na fase da Prova, constatouse que foi determinante a confecção de origamis em formato de cubo para a compreensão dos conceitos geométricos trabalhados. Depreendeu-se que o objetivo da oficina foi alcançado, tendo em vista que os participantes compreenderam a relação entre as formas produzidas em Origami e o ensino de Geometria, além disso, os mesmos, se sentiram interessados a usar essa técnica durante as suas práticas em sala de aula.

Palavras-chave: Sequência Fedathi; Origami; Geometria; DIMA.

\begin{abstract}
This article is a descriptive-exploratory study of the experience report type and aims to present the results obtained in the workshop: "Origami, Geometry and Fun", held at the VIII Dialogues of Mathematics with Pedagogy (DIMA). The methodological procedure of this workshop was based on the assumptions of the Fedathi Sequence (SF) methodology, based on its phases: Position taking, Maturation, Solution and Proof; and it took place through research in the classroom, using the observation of subjects and the application of an evaluative questionnaire as data collection techniques. As main results, it was observed that in the Taking of Position, with the proposed problem-situation, the participants, mainly students of the Pedagogy Course of the Faculty of Education of the Federal University of Ceará, had difficulties in identifying the geometric concepts in the Origami and that in the Proof phase, it was found that the making of cubeshaped origami was crucial for the understanding of the geometric concepts worked. It appeared that the objective of the workshop was achieved, considering that the participants understood the relationship between the forms produced in Origami and the teaching of Geometry, in addition, they felt interested in using this technique during their practices in classroom.
\end{abstract}

Keywords: Fedathi Sequence; Origami; Geometry; DIMA. 


\begin{abstract}
Resumen
Este artículo es un estudio descriptivo-exploratorio del tipo relato de experiencia y tiene como objetivo presentar los resultados obtenidos en el taller: "Origami, geometría y diversión", realizado en el VIII Diálogos de Matemáticas con Pedagogía (DIMA). El procedimiento metodológico de este taller se basó en los supuestos de la metodología Fedathi Sequence (SF), con base en sus fases: Toma de posición, Maduración, Solución y Prueba; y se llevó a cabo mediante la investigación en el aula, utilizando la observación de sujetos y la aplicación de un cuestionario evaluativo como técnicas de recolección de datos. Como principales resultados, se observó que en la Toma de Posición, con la situación-problema propuesta, los participantes, principalmente estudiantes del Curso de Pedagogía de la Facultad de Educación de la Universidad Federal de Ceará, tuvieron dificultades para identificar los conceptos geométricos en el Origami y que en la fase de Prueba, se encontró que la elaboración de origami en forma de cubo era crucial para la comprensión de los conceptos geométricos que funcionaban. Parecía que el objetivo del taller se logró, considerando que los participantes entendieron la relación entre las formas producidas en Origami y la enseñanza de la Geometría, además, se sintieron interesados en utilizar esta técnica durante sus prácticas en el aula.
\end{abstract}

Palabras clave: Secuencia Fedathi; Origami; Geometría; DIMA.

\title{
1. Introdução
}

A Matemática se torna uma disciplina ainda mais complexa quando, no momento do seu processo de ensino, ela não é contextualizada, nem trabalhada de forma concreta com vistas a alcançar os objetivos de aprendizagem dos estudantes. Santos (2015, p. 4) justifica isso quando nos diz que "a Matemática é uma das áreas do conhecimento mais difíceis de compreensão, por ser baseada em raciocínio crítico e lógico, contudo ela é uma disciplina onde se buscam os resultados dentro de si, para desenvolver o senso crítico e autonomia".

O ensino de Geometria é consonante a esse pensamento, pois, nas suas práticas, os professores já se utilizam de metodologias e recursos, tanto analógicos, como digitais, que torna tangível a abstração dos conceitos mais elementares, tais como aresta, face e vértice, por exemplo; principalmente em atividades que permitem aos estudantes o manuseio dos entes matemáticos, como os sólidos feitos em Origami, além de instigá-los ao desenvolvimento da autonomia e criatividade durante a aula.

Segundo Freitas (2016) essa autonomia se dá quando o estudante manipula esse material e ressalta que "a utilização de recursos concretos e lúdicos no ensino da matemática pode trazer ganhos na significação dos conteúdos, permitindo que o aluno faça a apropriação do conhecimento e tenha uma aprendizagem mais eficaz.” (Freitas, 2016, p. 12).

O Origami é a arte tradicional japonesa de dobrar papel, foi desenvolvida no Japão em torno do século VIII e proporciona atividades manuais valorizando a criatividade através da manipulação com o papel. As dobraduras realizadas permitem que o aluno possa explorar também vários conceitos de Geometria Plana e Espacial, além de trabalhar a interdisciplinaridade com a Arte, História e Matemática. Em seus estudos, a autora Ivani Fazenda (2015, p. 9) afirma que "se definirmos interdisciplinaridade como atitude de ousadia e busca frente ao conhecimento, cabe pensar aspectos que envolvem a cultura do lugar onde se formam professores.”

Em sua pesquisa, Rancan (2011) buscou investigar as possibilidades de se utilizar o Origami como apoio para o ensino de Geometria aliado à tecnologia e obteve como resultado que, propostas metodológicas que incluam o uso de materiais concretos em consonância com os recursos de comunicação utilizados nesta era digital, no caso um Blog, facilitam o entendimento e o estudo dos alunos, além de facilitar e aproximar a comunicação da turma entre si e com o professor. Já o trabalho de Freitas (2016) objetiva estimular a inserção do uso do Origami no estudo de Geometria, porque este faz conexão com os diversos ramos da matemática e apresenta ainda um forte apelo motivacional no dia a dia escolar contribuindo para o aprimoramento do ensino da mesma.

A partir dessas reflexões, durante o evento "VIII Diálogos da Matemática com a Pedagogia (DIMA)", que aconteceu na Faculdade de Educação da Universidade Federal do Ceará (FACED/UFC), realizou-se uma oficina para confecção de 
Origamis com formas geométricas, a fim de proporcionar aos professores de Matemática do Ensino Fundamental o conhecimento do uso do Origami como um dos recursos didáticos para o ensino de Geometria.

O VIII DIMA aconteceu presencialmente no ano de 2019, porém nos anos de 2020 e 2021 foi realizado em formato virtual, devido ao isolamento causado pela pandemia de COVID-19. Ele acontece anualmente, promovido pelo Grupo Tecendo Redes Cognitivas de Aprendizagem (G-TERCOA), aprovado no Conselho Nacional de Desenvolvimento Científico e Tecnológico (CNPq) e ligado à Faculdade de Educação (FACED) da UFC. (Menezes, Bezerra \& Santos, 2020).

Esse evento fomenta a discussão da formação do professor que ensina Matemática na Educação Básica e se justifica pela importância do tema e das possibilidades do encontro da Matemática com a Pedagogia diminuindo as distâncias epistemológicas e tem como público-alvo principal, os estudantes do curso de licenciatura em Pedagogia e em Matemática, professores da Educação Básica e do Ensino Superior, além de interessados na temática de forma geral.

Neste texto, objetiva-se apresentar os resultados obtidos a partir da realização da Oficina de Origami no VIII DIMA. Foi dividido em seções temáticas. Além desta Introdução, apresenta-se, na primeira seção, a fundamentação teórica realizada para ministração da oficina, trazendo a relação entre o ensino de Geometria, a confecção de Origamis e a sua importância.

Na segunda e na terceira seção, detalhou-se a metodologia utilizada para a ministração da oficina e a descrição do seu desenvolvimento. Na quarta seção, tratou-se da discussão e dos resultados obtidos com a realização da oficina, com o intuito de validar o objetivo deste artigo.

$\mathrm{Na}$ última seção, apresentaram-se as considerações dos autores, fomentando futuras e possíveis discussões em relação ao uso de tecnologias para o ensino de Geometria, indo além das atividades propostas pelos livros didáticos.

A seguir, apresentam-se algumas considerações sobre a relação do Origami com o ensino de Geometria, de modo a fundamentar esse trabalho.

\section{O Ensino de Geometria e o Origami}

Quando o assunto é o ensino de Matemática, há sempre muitas dúvidas a serem respondidas, a começar por qual conteúdo deve ser apresentado ao estudante e em qual ordem. Conforme (Xavier et al, 2021, p.2), "a Geometria trata das formas geométricas presentes nas construções de vários instrumentos e materiais encontrados no nosso cotidiano, mostra que é necessário entender melhor as ideias de construções, medições, conceitos de área, perímetro e ângulos, definições que causam dúvidas nos discentes.”

Nas matrizes curriculares tradicionais, no século XX, a Geometria era vista no fim do ano letivo e trabalhada com um foco completamente separado da Álgebra, de forma a apresentá-la apenas com demonstrações e teoremas, além das fórmulas muito complexas e abstratas. O fato é que, nesse contexto, o abandono do ensino de Geometria privava os alunos de desenvolverem integralmente os processos de pensamento necessários à resolução de problemas matemáticos Pavanello (1993).

O trabalho com Geometria pode proporcionar o desenvolvimento de um cidadão com pensamento crítico e autônomo, o que de certa forma justificava sua quase ausência na época, quando Pavanello (1993, p. 16) afirmou que o abandono do ensino de geometria deveria ser entendido, "como uma decisão equivalente às medidas governamentais, em seus vários níveis com relação à Educação" e ainda complementa quando diz que se poderia questionar as verdadeiras intenções e compromissos que essas medidas revelam em relação ao oferecimento de melhores oportunidades educacionais a todos os segmentos da população brasileira Pavanello (1993).

A Geometria ganhou espaço e visibilidade no nosso país, na reforma curricular de matemática dos anos 90, embora ainda tenha sido tímida a sua participação no currículo em ação. (Rodrigues \& Bernardo, 2011, p. 339). Atualmente, as orientações curriculares priorizam a Geometria porque consideram a importância do desenvolvimento da visualização e do 
raciocínio espacial, além de relacioná-la com outras unidades temáticas, Álgebra e Números (BNCC, 2018), proporcionando aos estudantes uma compreensão mais ampla e interdisciplinar, assim como o desenvolvimento do seu raciocínio matemático.

Para Rancan (2011, p. 14-15), "por meio do ensino da Geometria existe a possibilidade da estimulação da participação ativa do aluno no processo de ensino, construindo suas próprias percepções em relação aos conteúdos de Geometria". "A Matemática e as Ciências da Natureza são ciências que têm muitos pontos de contato, sendo, no entanto, por vezes necessário um olhar mais demorado na sua procura. Essa interdisciplinaridade pode ser explorada como um recurso valioso pelo educador, durante o processo de aprendizagem, tornando-o mais motivador e eficiente." (Silva, 2016, p. 461).

De acordo com a Base Nacional Comum Curricular (BNCC) (2018, p. 272) “A Geometria não pode ficar reduzida a mera aplicação de fórmulas de cálculo de área e de volume nem a aplicações numéricas imediatas de teoremas sobre relações de proporcionalidade em situações relativas a feixes de retas paralelas cortadas por retas secantes ou do teorema de Pitágoras.”

A BNCC propõe também que o ensino da Geometria possa ser ampliado de forma que o trabalho com Geometria possibilite o desenvolvimento de competências como as de experimentar, representar e argumentar, além de estimular a criatividade. Durante o ensino da Geometria, faz-se necessário repensar a prática do professor que ensina matemática e numa perspectiva de potencializar essa prática de forma mais lúdica e prazerosa, propõe-se a utilização do Origami.

O trabalho com o Origami no ensino de Geometria pode fazer toda a diferença. Segundo Piaget (1978), o estudante precisa vivenciar a Matemática e suas demonstrações com um contato direto com a realidade, ou seja, tendo em mãos algo de concreto, pois será por meio desse contato que ele irá aguçar a sua criatividade. Dentro desse contexto é que o autor Silva (2016) relata que a parte artística do origami poderá ajudar o aluno no desenvolvimento dessa criatividade, pois "no campo das Artes, por exemplo, ela pode ser utilizada de forma lúdica, valorizando seus componentes gráficos e possibilitando ao aluno um aprendizado numa abordagem mais prática e interativa”. (Silva, 2016, pp. 46-462). O autor ainda afirma que essa técnica é um ótimo recurso, pois ao utilizar formas geométricas para construção artística de figuras bem como de objetos com papel colorido, torna-se útil no enriquecimento do ensino e na aprendizagem de conceitos geométricos.

De acordo com os estudos de Rancan (2011), a beleza da Matemática está na possibilidade de interação entre Ciência e Arte e através do Origami é possível construir diversas formas geométricas que facilitam a sua compreensão. Alia-se o caráter lúdico ao cognitivo desenvolvendo assim atividades manuais, nas quais exigem observação e disciplina no cumprimento de etapas, construindo e reconstruindo seus conceitos, aproveitando o fascínio da arte. Os estudos de Bettin \& Pretto (2017) mostram que o trabalho com o Origami em sala de aula, além de trabalhar os conteúdos matemáticos como medidas, formas geométricas e suas propriedades, pode de forma interdisciplinar, abordar também os conteúdos de história como a Segunda Guerra Mundial, bombas atômicas, cultura japonesa, preservação do meio ambiente e a paz.

Conforme Dias, Vebber e Fronza (2019, p.114), “com o emprego do Origami, examinam-se comparações para compreender os conceitos geométricos, pois essas ações facilitam a sua compreensão, internalização e memorização.” É com essa vivência que os estudantes passam a perceber concretamente a Matemática e a ter afinidades com o assunto de Geometria e a mudança de postura docente é fundamental nesse processo de ruptura de paradigma e isso requer do professor, ações, tanto reflexivas, quanto procedimentais em relação a sua prática pedagógica.

A seguir, apresenta-se a metodologia deste trabalho, com os conceitos de oficina pedagógica e Sequência Fedathi (SF), metodologia esta, que possui em seus fundamentos e princípios, elementos que possam favorecer essa mudança.

\section{Metodologia}

O estudo aqui apresentado é descritivo-exploratório com abordagem qualitativa, tipo Relato de Experiência (RE). De acordo com Daltro e Faria (2019, p.229), “o RE caracteriza-se por uma multiplicidade de opções teóricas e metodológicas; e valoriza a explicitação descritiva, interpretativa e compreensiva de fenômenos, circunscrita num tempo histórico". 
A oficina "Origami: Geometria e Diversão" foi realizada no dia 28 de novembro de 2019, na Faculdade de Educação (FACED) da Universidade Federal do Ceará durante o evento VIII Diálogos da Matemática com a Pedagogia (DIMA), promovido pelo grupo de estudos e pesquisa Tecendo Redes Cognitivas de Aprendizagem (G-TERCOA) e contou com a participação de três alunos da graduação em Pedagogia, dois professores graduados no mesmo curso e um professor licenciado em Matemática.

A oficina teve a duração de duas horas e foi ministrada por um professor da rede pública estadual, especialista em Matemática, que já possuía experiência na confecção e utilização do Origami como recurso estratégico no ensino de Geometria.

Como técnicas de coleta de dados, usou-se a observação dos sujeitos registrada devidamente em um diário de campo, após o término da oficina, a aplicação de um questionário para avaliação e registros fotográficos. Conforme Appolinário (2012, p. 164), "qualquer que seja o processo de coleta, o fato é que, em geral, as pesquisas qualitativas geram uma enorme quantidade de informações que precisam ser organizadas".

De acordo com Santos (2007, p. 59), “A Oficina pedagógica é a participação responsável para a produção de um trabalho coletivo, em que, dentro de um espaço cada sujeito é responsável direto na execução de uma atividade coletiva.” Dessa forma, o sujeito se torna o protagonista, participando ativamente na construção do saber.

Para o desenvolvimento da oficina, utilizou-se a Metodologia Sequência Fedathi (SF), desde a etapa do planejamento da Sessão Didática (SD) até a execução teórico-prática atendendo as suas fases: Tomada de posição, Maturação, Solução e Prova (Souza, 2013). ${ }^{1}$

A SF propõe a quebra de "velhos paradigmas" que ocorrem em sala de aula e que envolvem a relação dos processos de ensino e aprendizagem, principalmente no que tange à mudança de postura do professor. De acordo com Santos (2017, p.84), "a SF tem como princípio teórico contribuir para que o Professor supere os obstáculos epistemológicos e didáticos que ocorrem durante a abordagem dos conceitos matemáticos em sala de aula".

\subsection{A oficina Origami: Geometria e Diversão}

Iniciou-se a oficina com uma sondagem feita pelo professor-formador a partir de perguntas relacionadas a experiência dos participantes em relação ao tema, de modo a melhor direcionar as atividades que seriam propostas no decorrer da mesma, o que na SF é o Plateau - "que será o ponto de partida comum na condução do estudo" (Pinheiro \& Pinheiro, 2017, p. 32).

Quadro 1 - Sondagem inicial.

\begin{tabular}{|l|l|}
\hline & \multicolumn{1}{|c|}{ Perguntas } \\
\hline 1 & O que vocês sabem sobre o Origami? \\
\hline 2 & Alguém já utilizou em suas práticas pedagógicas como recurso para o ensino de Geometria? \\
\hline
\end{tabular}

Fonte: Autores.

Logo em seguida, houve uma apresentação de slides feitos em Powerpoint para abordar o contexto histórico da confecção de Origamis e os conceitos geométricos que podem ser desenvolvidos a partir da observação e manuseio deste material, trabalhando de forma interdisciplinar outros conteúdos além dos conceitos matemáticos, como arte e história.

\footnotetext{
${ }^{1}$ Para uma maior compreensão ler o livro "Sequência Fedathi, uma proposta para o Ensino de Ciências e Matemática.
} 
Figura 1 - slides da oficina.

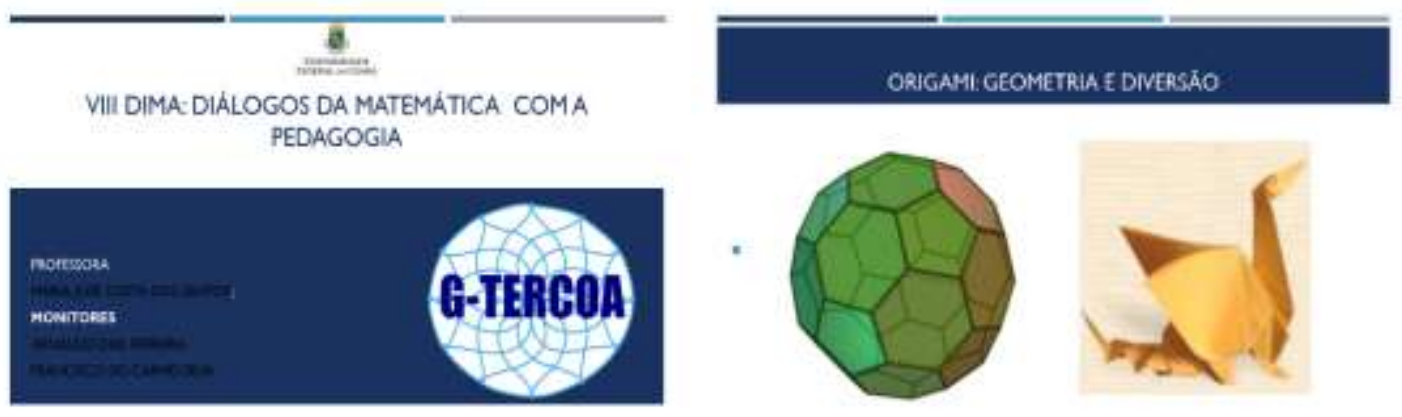

Fonte: Autores.

Após os slides, vários origamis foram expostos em uma mesa (Figura 2) e os participantes foram convidados a manusear e a identificar os tipos de figuras planas, sólidos e conceitos geométricos que poderiam ser explorados com a utilização destes, configurando a Tomada de Posição na SF. De acordo com Souza (2013, p. 20) "a situação-problema deve ter relação com o conhecimento a ser ensinado e que deverá ser apreendido pelo aluno ao final do processo".

Figura 2 - Origamis.

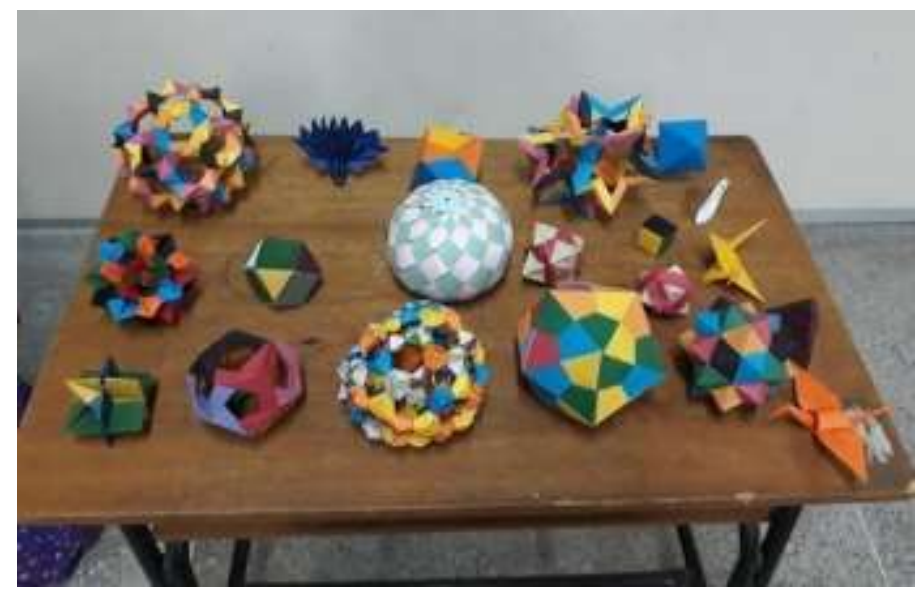

Fonte: Autores.

Várias perguntas surgiram durante o momento da Maturação nessa atividade. Um participante perguntou: "É preciso que seja tão colorido?" Outro: "Podemos encontrar triângulos, pirâmides, quadrados etc.? Parece muito difícil de construir". "Esse daqui é um poliedro?" O professor-formador respondeu com um contraexemplo: "O que caracteriza um poliedro?" e incentivou os participantes, instigando-os ao raciocínio. De acordo com Souza (2013, p.23), nesta fase "os alunos devem buscar compreender o problema e tentar identificar os possíveis caminhos que possam levá-lo a uma solução".

A fase Solução consolidou-se após as possíveis respostas da situação-problema apresentada. O professor-formador fez as demonstrações manuseando os origamis utilizados pelos participantes, explicando os conceitos conforme o que foi relatado e foi adicionando mais informações que passaram, por eles, despercebidas.

Nesse momento, foram trabalhados os conceitos de: vértice, face e aresta, além dos conceitos de área, volume e superfície, relacionados à geometria plana e espacial. Foram abordados também as nomenclaturas dos sólidos e figuras planas. Para Souza (2013, p. 29), “é importante que, durante a realização dessa etapa, aconteçam as trocas de ideias, opiniões e discussões dos pontos de vista e modelos propostos entre os alunos". 
A Prova, ponto de culminância na SF, se deu com o convite do professor-formador para que os participantes (Figura 3) pudessem construir um origami simples em formato de um cubo, a partir de duas folhas de papel ofício. Logo em seguida, eles relataram como poderiam utilizar esse material com seus alunos. Um dos participantes disse: "precisamos aprender primeiro a construir os sólidos geométricos para depois trabalhar com os alunos em sala de aula, pois essa construção é muito complexa". Outro participante relatou que: "seria interessante montar um clube do Origami para trabalhar os conceitos geométricos de forma lúdica".

Conforme Souza (2013, p. 33), “a didática do professor será determinante para aquisição do conhecimento por parte dos alunos", pelo fato de que é necessário manter a atenção, o interesse e a motivação do grupo; dessa forma o professor precisará fazer o intercâmbio entre os modelos apresentados e o modelo matemático científico a ser apreendido (Souza, 2013).

Figura 3 - confecção de origami.

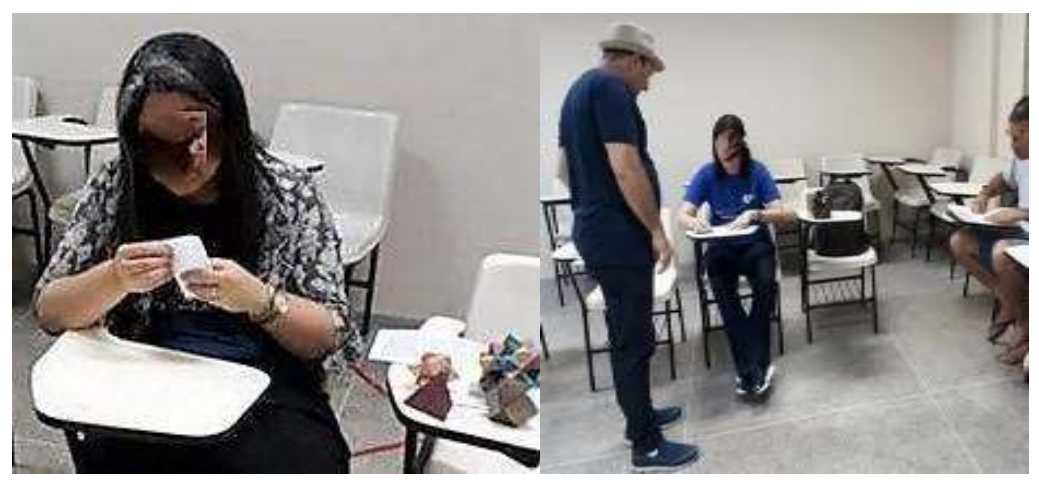

Fonte: Autores.

Para a avaliação, ao término da oficina, foi entregue um questionário impresso com perguntas relativas à sua execução para que os participantes pudessem sugerir ideias de modo a melhorar o planejamento para as próximas oficinas.

Quadro 2 - Tópicos referentes ao questionário de avaliação.

\begin{tabular}{|c|l|}
\hline 1 & Na sua opinião, enumere os pontos positivos da oficina. \\
\hline 2 & Na sua opinião, enumere os pontos de atenção da oficina. \\
\hline 3 & Enumere algumas sugestões para aprimoramento dessa ou de outras futuras oficinas \\
\hline
\end{tabular}

Fonte: Autores.

Buscou-se de forma qualitativa, utilizando-se da metodologia Sequência Fedathi, também para analisar os dados gerados pelas observações feitas pelo mediador durante a oficina e pelo questionário de avaliação (Quadro 2), com o apoio dos estudos de Sousa (2015) e Rancan (2011). A análise das respostas referentes às perguntas deste questionário, assim como das observações registradas no diário de campo serão apresentadas na seção resultados e discussão, a seguir.

\section{Resultados e Discussão}

A Sequência Fedathi nos propõe dois tipos de análise: ambiental e teórica. (Sousa, 2015). A análise ambiental atende basicamente ao plateau e este propôs, no princípio da oficina, uma sondagem inicial e de acordo com as respostas obtidas verbalmente e registradas no diário de campo, constatou-se que todos os participantes conheciam o Origami, mas nenhum deles havia utilizado como recurso pedagógico. 
Durante a execução da oficina, observou-se que na Tomada de Posição com a situação-problema apresentada, os participantes, principalmente os alunos da graduação em Pedagogia, tiveram dificuldades em identificar os conceitos geométricos nos Origamis que estavam dispostos sobre a mesa. De acordo com os pesquisadores, Borges Neto e Santos (2006), a formação do pedagogo precisa ser mais bem estruturada, pois esse profissional vai lecionar Matemática nos anos iniciais do Ensino Fundamental, com alguns conceitos construídos de forma equivocada, ainda na educação básica.

$\mathrm{Na}$ fase da Prova constatou-se que, a partir da observação dos sujeitos e dos registros feitos no diário de campo, foi determinante a confecção do Origami em formato de cubo pelos participantes para a compreensão dos conceitos geométricos relacionados, atendendo aos objetivos da oficina que foi apresentar o Origami aos professores de Matemática do Ensino Fundamental como um dos recursos didáticos para o ensino de Geometria.

A análise das respostas do questionário de avaliação mostrou que quanto aos pontos positivos da oficina, os participantes avaliaram que o Origami incentiva a criatividade, a elaboração de sequências de atividades e organização do pensamento, como também promove interação e socialização no grupo, desenvolvendo as habilidades motoras. "Este mesmo material que geralmente não é considerado didático pode se tornar um bom aliado para as descobertas, estudos e a construção do conhecimento" (Rancan, 2011, p. 19).

Quanto aos pontos de atenção, os participantes avaliaram que tiveram dificuldade em utilizar as medidas corretas para fazer as dobraduras, deixando o objeto fora do padrão e em conseguir acompanhar o professor-formador na execução da dobradura, por falta de práticas manuais.

Rancan (2011, p. 9), afirma que "as dobraduras de papel prometem ser um ambiente rico e desafiador para o trabalho com alunos e ressaltam a importância de se desenvolver de forma lúdica e concreta determinados conceitos geométricos”.

Quanto às sugestões para o aprimoramento das oficinas, os participantes avaliaram que a oficina deveria ter tempo de duração superior a duas horas pelo fato da complexidade da confecção de Origamis, que além de ser uma atividade que demanda um tempo de aprendizado, desperta nos participantes um desejo em desenvolver mais de uma forma, reafirmando o que diz Santos (2007, p. 59) quando se refere à sua importância: “a oficina pedagógica proporciona ao sujeito em atividade a chance de ser o protagonista da atividade que desenvolve".

\section{Considerações Finais}

Este artigo tem como objetivo principal apresentar os resultados obtidos a partir da realização da Oficina de Origami no VIII DIMA. A oficina pedagógica busca apoio nos conhecimentos adquiridos anteriormente na interação social, pois desencadeia um trabalho colaborativo e proporciona, de acordo com o tempo e espaço, um leque de situações de ensino e aprendizagem através de um trabalho em comum (Santos, 2007).

Depreendeu-se que o objetivo da oficina foi alcançado, tendo em vista que os participantes conseguiram compreender a relação entre as formas produzidas em Origami e o ensino de Geometria, além disso, eles se sentiram interessados em usar essa técnica durante as suas práticas em sala de aula. Foi importante que essa prática levasse os professores à reflexão de que é preciso encontrar outros meios de integração da tecnologia em sala de aula que não sejam só as atividades propostas pelos livros didáticos (Amaral-Schio, 2018). Ressalta-se também que o evento Diálogos da Matemática com a Pedagogia, promovido anualmente, é fundamental e relevante para proporcionar uma maior aproximação entre os estudantes de Pedagogia e a Matemática, minimizando a distância entre o seu ensino e a negação em relação a ela.

Considerou-se que a proposta da oficina foi pedagogicamente viável, pois apresentou e refletiu com os participantes sobre o ensino de Geometria com a utilização do recurso do Origami, e a partir da visualização dos objetos geométricos, eles passaram a internalizar os conceitos necessários para a aprendizagem significativa desse conteúdo. 
Concluiu-se, portanto que o Origami pode despertar ainda nos participantes, um interesse maior pela Matemática, e por ter no papel, mesmo nos mais simples, a sua principal matéria-prima, seu custo se torna acessível a todos, além de ser de fácil manuseio e ecologicamente ser um recurso sustentável. E ainda que o trabalho pedagógico com dobraduras proporciona ao professor uma interação real com a geometria plana e espacial, subsidiando a sua formação docente de modo a desenvolver uma abordagem interessante e principalmente lúdica em sala de aula. Ao propor essas construções, estará estimulando, nos alunos, a visão dos conceitos matemáticos que são fundamentais para o entendimento dos mesmos.

\section{Referências}

Amaral-schio, R. B. (2018). Livro Didático de Ensino Médio, Geometria e a presença das Tecnologias. Renote, 16(2). https://www.seer.ufrgs.br/renote/article/view/89217

Appolinário, F. (2012). Metodologia da Ciência: filosofia e prática da pesquisa. (2a ed.), Cengage Learning.

Bettin, A. D. H., \& Pretto, V. (2017, May). O Origami no ensino e aprendizagem de matemática. In VII Congresso Internacional de Educação-Educação Humanizadora: valorizando a vida na sociedade contemporânea. 1(1), 1.

Borges Neto, H. \& Santos, M. J. C. (2006). O desconhecido das operações concretas e os números fracionários. In: Vasconcelos, J.G; Soares, E. L.R. \& Carneiro, I. M. S. P. (orgs.). Entre tantos: diversidade na pesquisa educacional. Fortaleza: Editora UFC, 190-199.

Brasil. Base Nacional Comum Curricular. (2018). Versão final. Brasília: Ministério da Educação.http://basenacionalcomum.mec.gov.br/images/BNC C_EI_EF_110518_versaofinal_site.pdf

Daltro, M. R. \& Faria, A. A. (2019). Relato de experiência: Uma narrativa científica na pós-modernidade. Estudos e Pesquisa em Psicologia, Rio de Janeiro, v.19, n.1. p. 223-237. https://www.e-publicacoes.uerj.br/index.php/revispsi/article/view/43015/29726

Dias, C. De F.; Vebber, G. C. \& Fronza, J. (2019). Experimentação do origami no ensino da geometria. REMAT: Revista Eletrônica da Matemática, 5(2), 108122. https://periodicos.ifrs.edu.br/index.php/REMAT/article/view/3392

Fazenda, I. (2015). Interdisciplinaridade: Didática e Prática de Ensino. Interdisciplinaridade. Revista do Grupo de Estudos e Pesquisa em Interdisciplinaridade. ISSN 2179-0094, O(6), 9-17. https://revistas.pucsp.br/index.php/interdisciplinaridade/article/view/22623

Freitas, A. C. (2016) ORIGAMI: O uso como instrumento alternativo no ensino da geometria. Dissertação. UNESP São José do Rio Preto SP 59f.

Menezes, E. N.; Bezerra, F.A.L. \& Santos, M.J.C. (2020). IX DIMA on-line: uma experiência exitosa em período de pandemia. Olhar de professor, Ponta Grossa, 23, 1-6, e-.16139.209209228231.0715, https://www..org/jatsRepo/684/68464195040/68464195040.pdf

Pavanello, M. R. (1993). O abandono do ensino de geometria no Brasil: causas e consequências. Revista Zetetiké. Ano I - ${ }^{\circ}$ 1. https://periodicos.sbu.unicamp.br/ojs/index.php/zetetike/article/view/8646822/13724

Piaget, J. (1978). Psicologia e epistemologia por uma teoria do conhecimento. (2a ed.), Forense Universitária.

Pinheiro, A.C.M \& Pinheiro, T.S.M. (2017). Proposta Metodológica do uso do Ambiente Computacional como Recurso Didático para o ensino de Conceitos Matemáticos. In Borges Neto, H. (Org.). Sequência Fedathi no ensino de Matemática. Vol.1, Coleção Sequência Fedathi, Curitiba, Editora CRV.

Pires, C. M. C.; Curi, E. \& Campos, T. M. M. (2000). Espaço e forma: a construção de noções geométricas. PROEM,

Rancan, G. (2011). Origami e tecnologia: investigando possibilidades para ensinar geometria no ensino fundamental. Dissertação. Pontifícia Universidade Católica do Rio Grande do Sul, Porto Alegre. https://repositorio.pucrs.br/dspace/bitstream/10923/3101/1/000436223-Texto+Completo-0.pdf

Rodrigues, M. \& Bernardo, (2011). M. Ensino e Aprendizagem de Geometria. Anais do XXII SIEM. p. 339-344.

Santos, M. J. C. (2007). Reaprender Frações Por Meio de Oficinas Pedagógicas: Desafio Para a Formação Inicial. 2007. 90 f. Dissertação (Mestrado em Educação) - Faculdade de Educação, Universidade Federal do Ceará, Fortaleza.

Silva, C. (2016) Ciência e Arte: O origami no ensino da geometria: uma experiência interdisciplinar com alunos brasileiros no Japão in T., Pereira, A., A. Almeida, N., Vieira, M., C. Loureiro. Atas do VII Encontro do CIED - II Encontro Internacional, Estética e Arte em Educação. (460-471) Lisboa: CIED Centro Interdisciplinar de Estudos Educacionais.

Silva, C. (2015). A formação de Pedagogo para o Ensino da Matemática nos anos iniciais do Ensino Fundamental: reflexões dedutiva e epistemológica. XIV CIAEM-IACME, México, http://xiv.ciaem-redumate.org/index.php/xiv_ciaem/xiv_ciaem/paper/viewFile/1379/530

Silva, C. (2017). A formação do professor de matemática: metodologia Sequência fedathi(sf). Revista Lusófona de Educação, 38, 81-96 81 10.24140/issn.16457250.rle 38.05. https://revistas.ulusofona.pt/index.php/rleducacao/article/view/6261\#: :text=Este\%20trabalho\%20tem\%20como\%20ob jetivo,de $\% 20$ ensino $\% 20$ municipal\%20e\%20estadual.

Sousa, F. E. E. (2015). A pergunta como estratégia de mediação didática no ensino de Matemática por meio da Sequência Fedathi. 2015. 282p. Tese (Doutorado em Educação) - Faculdade de Educação, Universidade Federal do Ceará, Fortaleza.

Sousa, F. E. E. (2017). A pergunta como mediação. In: Borges Neto, H. (org.). Sequência Fedathi no ensino da matemática. Curitiba: CRV, 95 a 112. 
Research, Society and Development, v. 10, n. 8, e42410817423, 2021

(CC BY 4.0) | ISSN 2525-3409 | DOI: http://dx.doi.org/10.33448/rsd-v10i8.17423

Souza, M. J. A. (2013). Sequência Fedathi: apresentação e caracterização. In. Sousa, F. E. E. et al. (Org.). Sequência Fedathi: uma proposta pedagógica para o ensino de Ciências e Matemática. Fortaleza: Edições UFC.

Xavier, A. R. Barbosa, M. K. R., Muniz, K. R. de A., Andrade, F. A. de, Santana, J. R., Vasconcelos, J. G., Scipião, L. R. de N. P., Carvalho, E. de F. G. de, Ferreira, A. D., \& Santos, M. J. C. dos. (2021). Saberes populares, Etnomatemática e o uso de Jogos no ensino de Geometria. Research, Society and Development, 10(1), e50910111998. https://doi.org/10.33448/rsd-v10i1.11998. 